\title{
A Supply Chain Coordination Mechanism with Cost Sharing of Corporate Social Responsibility
}

\author{
Yong Liu *, Bing-ting Quan *, Jiao Li and Jeffrey Yi-Lin Forrest ${ }^{\mathbb{B}}$ \\ School of Business, Jiangnan University, Wuxi 214122, China; 6170905005@stu.jiangnan.edu.cn (J.L.); \\ Jeffrey.forrest@sru.edu (J.Y.-L.F.) \\ * Correspondence: liuy@jiangnan.edu.cn (Y.L.); 6160905009@vip.jiangnan.edu.cn (B.-t.Q.)
}

Received: 11 February 2018; Accepted: 11 April 2018; Published: 17 April 2018

\begin{abstract}
The competition of modern enterprises has shifted from brand competition among enterprises of the past to that of supply chains; and considering corporate social responsibility (CSR) within supply chain management has become an inevitable requirement for improving the competitiveness of enterprises and conforms to the trend of standardization of social responsibility guidelines. This paper deals with channel coordination and decision-making in a CSR supply chain that is comprised of a dominant retailer and $n$ homogeneous suppliers. The Stackelberg game is employed to analyze the optimal decision-making of this supply chain under either decentralized or centralized decision-making processes. After that, the thought and method of super conflict equilibrium are used to design the coordination decision-making mechanism of this supply chain based on the cost sharing of CSR to solve channel conflict and to optimize the decision. The results show that the proposed mechanism based on the cost sharing of CSR is better than those with only either the retailer or the suppliers being CSR; and it can well describe the relationship between the retailer and the suppliers, and increase the eagerness of the retailer and suppliers to carry out their CSR under various circumstances without having the profits adversely affected. As a matter of fact, this mechanism maximizes the profits of the entire supply chain system and also enhances the competitiveness of the chain.
\end{abstract}

Keywords: corporate social responsibility (CSR); cost sharing; social welfare; coordination; decision-making mechanism; super conflict equilibrium

\section{Introduction}

With the internationalization of economic development and the evolution of production technology, enterprises pursue growth and generate profits for their shareholders at a very fast pace, which has seriously impacted the environment and the society. Consequently, the enterprises are forced by stakeholder (such as employees, suppliers, retailers, consumers, government and Non-governmental organization) and shareholder to perform socially [1]. Consequently, CSR becomes an important issue to control the supply chain. Just as the concept of sustainability defined by Word Commission on Environment and Development (WCED): "it is a development that meets the needs of the present without compromising the ability of future generations to meet their own needs" [2], CSR is often used as a synonym of sustainability, Specifically, sustainability is expected goal of enterprises and CSR is the way to achieve it $[3,4]$. In recent years, faced with a series of problems, such as environmental pollution, labor conflicts, food safety and other issues due to the lack of CSR, more and more consumers tend to buy environmentally friendly products with public welfare and begin to resist products produced by enterprises that are known to lack humanistic care and employee protection [5]. In addition, stakeholders hope enterprises be more CSR for their operations [6]. At the same time, due to various pressures, such as the need for sustainable development as advocated 
by different countries and social organizations, enterprises have gradually realized the necessity of corporate social responsibility (CSR) and the importance of sustainable development. Practicing CSR has become a new normal of many enterprises. Some enterprises have carried out specific practices of CSR. For example, CR Vanguard (http:/ /www.crv.com.cn/whyzr/shzr/zrbg/), a large retailer, has published its "Corporate Social Responsibility Report" for six consecutive years, while detailing the changes it has made to the society and environment. Carrefour (http:/ / www.carrefour.com.cn/) has demonstrated its corporate social responsibility for food safety and humane care through its CSR Report. Wal-Mart (http:/ / www.wal-martchina.com/) and other retailers introduced CSR into their supply chain management by codes of conduct [7]. Especially in the current economic environment, the competition pattern has changed, and the competition among enterprises has evolved into that of supply chains so that no individual enterprise can be "alone" and closed from the society. The concept of CSR is no longer an internal problem of an individual enterprise; instead, it is closely related to the overall performance of the supply chain and the profits of the stakeholders. Murphy et al. explained CSR consideration in supply chains and other researchers showed the importance of CSR in supply chain decision-making with case studies [8]. Even so, socially responsible supply chains often provide suboptimal decisions and suboptimal performance because of the conflicting self-interested objectives of the channel members. Thus, how to design a reasonable supply chain coordination mechanism that can effectively encourage the supply chain members to undertake their CSR, and how to solve the CSR supply chain coordination problem have become urgent practical problems.

The main purpose of the paper is to design a CSR cost sharing mechanism to coordinate the supply chain, motivate supply chain members to actively assume social responsibility, and optimize the overall profitability of the supply chain. To do so, in our modeling, we only consider effects of CSR in the form of consumer surplus that a socially responsible firm performed for stakeholder's welfare. Thus, the total profit of a socially responsible firm is its traditional pure profit plus a share of consumer surplus accrued from its stakeholders [9-18]. Two cases, the retailer being socially concerned in one and the $n$ suppliers in the other, are discussed. In the retailer-Stackelberg game setting considering CS (cost-sharing) as the coordination mechanism, we analyze effects of CSR on the profits of the channel members and the effectiveness of the mechanism. In particular, this paper is designed to address the following questions. First, for both cases, what impact may CSR have on decentralized decisions and how does the socially responsible firm maximize its profit goal irrespective of other players' decisions and if a channel member is engaged in CSR, then what impact does it has on other member's pure profit? Second, does the CS mechanism resolve channel conflict and what conditions need to be satisfied? Third, under the CS mechanism, under what circumstances can CSR be fairly distributed CSR and how can consumer surplus be distributed among supply chain members?

The remainder of this paper is organized as follows: the model hypotheses are given in Section 3. Then, Section 4 discusses the supply chain decision-making mechanism under either decentralized decision-making or centralized decision-making. Section 5 constructs a novel supply chain coordination decision-making mechanism based on the cost sharing of CSR. A numerical case study is furnished in Section 6 to illustrate how the proposed mechanism can be practically applied. The paper is concluded with remarks in Section 7.

\section{Literature Review}

The literature is divided into two categories: the research on corporate social responsibility and the research on related mechanism/contracts of a socially responsible supply chain. This paper introduces CSR into a supply chain and explores how to coordinate this supply chain through the novel CSR cost sharing in this paper. CSR is an evolving and dynamic concept that currently does not have a universally accepted definition. Dyllick et al. defined CSR as meeting the needs of a firm's direct and indirect stakeholders (e.g., shareholders, employees, clients, pressure groups, communities, etc.) [1]. Carter et al. defined CSR as corporate activities and their impacts on different social groups, including human rights, environment protection, pollutant emission control, and 
philanthropy, to name a new [19]. Other than these scholars, some think CSR is something only related to social problems [20], while others only consider environmental issues [21]. Dahlsrud analyzed 37 definitions of CSR and developed five dimensions of CSR: environmental, social, economic, stakeholder, and voluntariness [22]. In Panda [23], CSR is defined as the responsibility of an organization for the impacts of its decisions and activities on society and the environment through transparent and ethical behavior that is consistent with sustainable development. Although definitions of CSR vary in the literature with times and CSR has become a determining decision factor to realize the sustainable development of enterprises, they bear no effect related to CSR on the application of this current study, where the focus is on how to integrate CSR, no matter how it is defined, into supply chain (SC), explore the relationship between CSR and decision-making of channel members and improve the efficiency and effectiveness of the supply chain by a novel mechanism. Therefore, this paper takes CSR as some decisions and activities (such as mitigating pollutant emission, improving working conditions, philanthropic donations, and so on) similar to literature [23] that is conducive to the sustainable development of the supply chain. For quantitative analysis, we consider the effect of the CSR in the form of consumer surplus in the modeling rather than the CSR activities that channel members perform.

Analyzing the research on the supply chain coordination mechanism, the literature mainly focuses on such aspects as pricing [24-28], quantity discount [29,30], information sharing [31,32], profit distribution [33-35], and cost sharing [36-40], analyzes supply chains under either centralized or decentralized decision-making, and provides coordination strategies. Although the literature on the supply chain coordination mechanism is rich, it rarely pays attention or neglects the CSR of supply chains, making it difficult for relevant CSR to satisfy the realistic requirements of supply chain management. In recent years, there has been a significant rise in interest over CSR for sustainability. In addition, application of CSR in supply chains has emerged in the two last decades. Considering a socially responsible supply chain, some scholars have established various models (or contracts). Commonly used coordination contracts include wholesale price, revenue sharing, two-part tariffs, flexible quantity discount, etc. Among them, Ni et al. [41] coordinated two level CSR supply chains with the wholesale price contract, though they did not discuss the issue of double marginalization. Yang et al. [42] designed a closed-loop supply chain coordination mechanism with CSR and gave a quantitative formula for CSR cost without considering its consumer surplus. Guo et al. [43] discussed the supply chain decision-making with CSR under three cases: Nash equilibrium, Stackelberg equilibrium, and cooperative game, and effectively realized the Pareto improvement of the supply chain through a revenue sharing mechanism. By comparing the effect of the two-part tariff mechanism and revenue-sharing mechanism on coordination, Gao et al. [44] maintained that both of these mechanisms could achieve coordination of the closed-loop supply chain and CSR. Hsueh [7] designed a new revenue sharing contract to improve the CSR performance in supply chain. Additionally, various scholars compared the supply chain performances with different decision-makers to be CSR in different situations. For example, Panda et al. [10-13,23] discussed channel coordination issues when the manufacturer and retailers have separate CSR, developed their revenue sharing contract based on the Stackelberg game to coordinate the secondary supply chain [23], and then adopted a contract consisting of two wholesale price discounts to solve the channel conflict coordination in a three-echelon supply chain with the manufacturer to be CSR [10]. Panda et al. used a quantity discount contract to solve the channel conflict in a two-echelon supply chain with only the retailer being CSR [11], and then proposed to share the consumer surplus brought out by CSR, although they did not quantify and characterize the effort or cost of undertaking CSR [12]. Subsequently, they quantified CSR and its impact, and proposed a revenue sharing contract to resolve the channel conflict [13]. Modak et al. $[14,15]$ exploited a new revenue sharing contract to coordinate a three-echelon supply chain consisting of a manufacturer with CSR, multi-distributors, and multi-retailers [14]. They analyzed the impacts of social responsibility on the retailers, and proved that the two-part tariff contract could solve the conflict of the supply chain [15]. The literature [9-15,41-44] has fully considered the consumer 
surplus caused by CSR but not the investment cost of CSR. Crifo et al. [45] analyzed the impact of different combinations of CSR on economic performance, and compared the results from the quality and quantity of CSR. Wu et al. [46] proposed two contracts, flexible quantity discount contract and wholesale price contract, in order to encourage suppliers to invest in CSR. Their results show that these two kinds of contracts under certain conditions could significantly improve the performance of the supply chain, which provides some reference for the design of a coordination decision-making mechanism in the following research.

From the literature reviewed above, it can be found that the literature on supply chain coordination contracts and mechanisms is very rich. Even so, the objectives of the paper differ from the prior works as follows. Firstly, it takes an operational view and a quantitative approach to comprehensively consider the costs and profits of CSR investments, where the costs are set as a quadratic function in sales volume instead of in variables with ambiguous meanings in Hsueh [9], and the profits of CSR are set as an accumulation form of consumer surplus by exhibiting corporate social responsibility. Secondly, this paper treats social responsibility as shared obligations among supply chain partners based on the stakeholder theory because unclear allocation is likely to lead to the "tragedy of the commons" and result in a less efficient supply chain [7]. Therefore, apart from the available literature [9-15,41-44,46], in this paper, different contracts are used in coordinating the supply chain, while using the Stackelberg game and the concept of super conflict equilibrium to design a novel supply chain coordination decision-making mechanism based on cost sharing of CSR to coordinate the channel and distribute the surplus profit among all channel members and obtain the optimal decisions for each member. This study not only enriches the theory of enterprise social responsibility supply chains, but also expands the application of cost-sharing mechanism in the coordination and decision-making of supply chains.

\section{Model Hypotheses}

Assumption 1. Assume that there exists a retailer-dominated supply chain composed of a dominant retailer and n homogeneous suppliers who consider CSR. Here, "CSR" is an evolving concept that does not have a universally accepted definition at present. Thus, it could be thought as some decisions and activities related with stakeholders and consistent with sustainable development. Let $D=\left\{d_{0}, d_{1}, d_{2}, \ldots, d_{n}\right\}$ be the set of risk neutral suppliers with $d_{0}$ being the dominant retailer.

Assumption 2. Although the products provided by different suppliers are homogeneous, their wholesale prices vary. Assume that $w_{i}, c_{i}, p_{i}$ stand for the wholesale price of the product provided by supplier $d_{i}(i=1,2, \ldots, n)$ to the retailer, the unit cost for supplier $d_{i}$ to manufacture the product, and the unit price for the retailer to sell the product from $d_{i}$ to a consumer, respectively. Let $q, q_{i}$ respectively represent the quantity of products provided by all suppliers and that provided by supplier $d_{i}$, satisfying $q=\sum_{i=1}^{n} q_{i}$. In addition, let $A$ and $\mu \in(0,1)$ stand for the consumer surplus and the CSR coefficients of the members, and $\mu=\mu_{1}=\mu_{2}=\ldots=\mu_{i}=\ldots=\mu_{n}$.

Assumption 3. There are no shortage and unsold products in the supply chain that consider CSR.

According to the principle of diminishing marginal utility, the demand decreases with increasing price. Thus, the relationship between the quantity of products provided by the suppliers to the retailer and the product price can be obtained as follows:

$$
q=a-b p
$$

Here, $a, b$ stand for the market potential demand, and the price sensitivity coefficient, respectively. For the homogeneous products, their price sensitivity to the market is consistent, that is, the price sensitivity coefficient is the same. Correspondingly, the relationship between the number of the 
homogeneous products provided by the suppliers to the retailer and the unit price of the product provided by the retailer to the consumer can be written as

$$
q_{i}=a_{i}-b p_{i}, i=1,2, \ldots, n,
$$

where $a_{i}, b$ stand for the potential demand for the product provided by the supplier $i$ and the price sensitivity coefficient, respectively, satisfying $a_{i}>0, a=\sum_{i=1}^{n} a_{i}$.

Because the specific measures adopted by the enterprises considering CSR are different, it is difficult to measure the impacts of CSR in the form of business rules and regulations [47]. To quantify CSR, let us exploit the performance of the enterprise's CSR investment activities, such as charitable donations, factory sewage treatment, staff working environment improvement, as the performance brought about by the enterprise's commitment to CSR is ultimately reflected in the increase in the sales volume of the enterprise. By learning from the representations of CSR costs considered by $\mathrm{Ni}$ et al. [41,48] and the Cobb's Douglas production function, these references point out that, although CSR is not directly related to the production and sales of enterprises, CSR behaviors or CSR efforts are conducive to establishing and maintaining the reputation of enterprises $[16,17]$, which help to indirectly increase market sales [28]. Thus, the CSR cost function associated with the $n$ suppliers' production can be given as follows:

$$
C(q)=c q^{2} / 2
$$

where $c$ expresses the unit cost of increasing production as a result of CSR related implementations.

Accordingly, if only the retailer or suppliers undertake CSR, their cost functions for the adopted CSR are written as follows:

$$
\begin{gathered}
C_{0}=\frac{1}{2} c \sum_{i=1}^{n} q_{i}^{2}, i=1, \ldots, n, \\
C_{i}=\frac{1}{2} c q_{i}^{2}, i=1, \ldots, n
\end{gathered}
$$

For the supply chain that considers CSR, although its members need to pay a certain cost for adopting CSR, consumers will be more likely to buy or would like to spend a higher price to buy products with CSR attributes [5] so that the enterprises can reap more profits. In general, the profits generated by adopting CSR can be characterized and measured in the form of consumer surplus that is accrued from the stakeholders [14,49-51], where consumer surplus is the difference between the maximum price that consumers are willing to pay for the product and the real price. Accordingly, the consumer surplus and the profits brought out by the CSR of the supply chain can be defined as follows.

Definition 1. Assume that there exists a retailer-dominant supply chain that considers CSR. For $q, a>0, b$, let $p_{\min }=\frac{a-q}{b}$ and $p_{\max }=\frac{a}{b}$. Then,

$$
\begin{gathered}
A=\int_{p_{\min }}^{p_{\max }} q d p \\
=\int_{\frac{a-q}{b}}^{\frac{a}{b}}[(a-b p) d p \\
=\frac{q^{2}}{2 b} \\
\quad R=\mu A
\end{gathered}
$$

is called the consumer surplus function and the revenue function of the enterprise undertook CSR, respectively, where $\mu \in(0,1)$ is the CSR coefficient.

In Definition $1, \mu \cong 0$ implies that the enterprise is not considered to be CSR, which means that the enterprise purely pursues its profit maximization; $\mu \cong 1$ represents the enterprise taking full account 
of the impact of CSR, which shows that the enterprise pursues its welfare maximization that consists of pure profits received through selling the product and consumer surplus, as well as the costs of CSR.

According to the above analysis, in order to solve the coordination problem of such a CSR supply chain that is composed of a dominant retailer and $n$ suppliers from the angle of cost sharing, we exploit the game analysis tool to establish a supply chain coordination model, and then utilize it to analyze the optimal decision-making of the profits, price and order quantity of the supply chain members under the decentralized and centralized decision-making, respectively, and explore a supply chain coordination decision-making mechanism based on cost sharing of CSR.

\section{Supply Chain Decision-Making Mechanism under Different Decision-Making Schemes}

\subsection{A Supply Chain Decision-Making Mechanism under Decentralized Decision-Making}

This section is divided into subsections and provides a concise and precise description of the research results, and their interpretations as well as the experimental conclusions drawn are provided in Sections 5 and 6.

In the retailer-dominated supply chain that considers CSR, the retailer and suppliers take the strategy of pursuing the maximization of their individual profits as their own goal to deal with the problem of optimal decision-making. If the decision-making is decentralized, considering how different stakeholders could undertake CSR, there exist two situations: the retailer is CSR alone, and the suppliers are CSR alone. With respect to the decentralized decision-making, we exploit a game model to analyze the optimal decision-making of the supply chain members.

\subsubsection{The Supply Chain Optimal Decision-Making If Only the Retailer Is CSR}

In the retailer-dominated supply chain with the retailer to be CSR alone, assume the retailer is in the core position of the supply chain. According to the Stackelberg game, after the retailer makes its optimal decision on the retail price and order quantities, the suppliers generally adopt follow-up strategies to optimize their individual decision objectives. According to the above assumptions, let $p_{r i}, w_{r i}, q_{r i}, \pi_{0}^{r}, \pi_{i}^{r}, \pi^{r}$ be the retail price, wholesale price and order quantity, respectively, and then the profit function of the retailer, suppliers and the whole supply chain, respectively. Then, the expressions of the profit functions of the retailer, suppliers, and the whole supply chain, where only the retailer is CSR can be written as:

$$
\begin{gathered}
\pi_{0}^{r}=\sum_{i=1}^{n}\left(p_{r i}-w_{r i}\right) q_{r i}+\frac{1}{2 b} \mu \sum_{i=1}^{n} q_{r i}^{2}-\frac{1}{2} c \sum_{i=1}^{n} q_{r i}^{2}, i=1, \ldots, n \\
\text { s.t. }\left\{\begin{array}{c}
\mu A \geq C(q) \\
0<\mu<1
\end{array},\right. \\
\pi_{i}^{r}=\left(w_{r i}-c_{i}\right) q_{r i}, i=1, \ldots n, \\
\pi^{r}=\pi_{0}^{r}+\sum_{i=1}^{n} \pi_{i}^{r}, i=1, \ldots n .
\end{gathered}
$$

Theorem 1. Assume that $p_{r i}^{*}, q_{r i}^{*}, w_{r i}^{*}$ stands for the optimal retail price, order quantity, and wholesale price of the supply chain, respectively. Then, for $p_{r i}, w_{r i}, q_{r i}, \mu, a, b, c, a_{i}, c_{i}$, satisfying $\mu \geq b c$ and $\sum_{i=1}^{n} a_{i}=a$, if only the retailer undertakes CSR, and then the following hold true:

$$
\begin{gathered}
p_{r i}^{*}=\frac{a_{i}(2 b c-2 \mu+3)+b c_{i}}{2 b(b c-\mu+2)}, \\
q_{r i}^{*}=\frac{a_{i}-b c_{i}}{2(b c-\mu+2)},
\end{gathered}
$$




$$
w_{r i}^{*}=\frac{a_{i}+b c_{i}}{2 b} .
$$

Proof. With respect to Equation (8), setting its partial derivative on variable $p_{r i}$ and making it equal to zero produce

$$
\frac{\partial \pi_{0}^{r}}{\partial p_{r i}}=\left(a_{i}-b p_{r i}\right)(1+b c-\mu)-b\left(p_{r i}-w_{r i}\right)=0 .
$$

Solving this equation gives the retail price $p_{r i}=\frac{a_{i}(1+b c-\mu)+b w_{r i}}{b(b c-\mu+2)}$, and substituting $p_{r i}$ into the demand function $q_{i}=a_{i}-b p_{i}$ leads to the order quantity $q_{r i}=\frac{a_{i}-b w_{r i}}{b c-\mu+2}$. By substituting $p_{r i}$ and $q_{r i}$ into Equation (9), solving the partial derivative of Equation (9) for variable $w_{r i}$ and making it equal to zero, we obtain:

$$
\frac{\partial \pi_{i}^{r}}{\partial w_{r i}}=\frac{a_{i}+b\left(c_{i}-2 w_{r i}\right)}{b c-\mu+2}=0
$$

from which the optimal wholesale price $w_{s i}^{*}=\frac{a_{i}(b c-\mu+2)+2 b c_{i}}{b(b c-\mu+4)}$ is determined. Similarly, putting this optimal price into the expressions of the retail price and order quantity, the optimal retail price and order quantity can be obtained as follows:

$$
\begin{gathered}
p_{r i}^{*}=\frac{a_{i}(2 b c-2 \mu+3)+b c_{i}}{2 b(b c-\mu+2)}, \\
q_{r i}^{*}=\frac{a_{i}-b c_{i}}{2(b c-\mu+2)} .
\end{gathered}
$$

Based on the optimal retail price $p_{r i}^{*}$, order quantity $q_{r i}^{*}$, and wholesale price $w_{r i}^{*}$, the profits of the retailer, suppliers and the whole supply chain with only the retailer being CSR can be acquired as:

$$
\begin{aligned}
& \pi_{0}^{r *}=\frac{\sum_{i=1}^{n}\left(b c_{i}-a_{i}\right)^{2}}{8 b(b c-\mu+2)}, \\
& \pi_{i}^{r *}=\frac{\left(b c_{i}-a_{i}\right)^{2}}{4 b(b c-\mu+2)}, \\
& \pi^{r *}=\frac{3 \sum_{i=1}^{n}\left(b c_{i}-a_{i}\right)^{2}}{8 b(b c-\mu+2)} .
\end{aligned}
$$

For such a dominant-retailer supply chain with only the retailer being CSR, what form does the relationship among the decision-making variables of the retail price, order quantities, and profits of the supply chain members, the total supply chain, and CSR take on? What is the magnitude of relevant influence? According to the previous model analysis, the following theorem can be given.

Theorem 2. In the retailer-dominated supply chain with only the retailer being CSR, the following hold true:

1. The retail price is negatively correlated with the CSR coefficient $\mu$;

2. The order quantity is positively correlated to the CSR coefficient $\mu$;

3. The wholesale price has nothing to do with the CSR coefficient $\mu$; and

4. The profit of each member of the supply chain and the whole supply chain are positively correlated with the CSR coefficient $\mu$. 
Proof. In order to explore the relationship between these decision-making variables and CSR, let us compute the partial derivatives of the retail price, order quantity, profits of the supply chain member, and the total supply chain with respect to the CSR coefficient $\mu$ as follows:

$$
\begin{aligned}
\frac{d p_{r i}}{d \mu} & =\frac{\left(b c_{i}-a_{i}\right)}{2 b(b c-\mu+2)^{2}}, \\
\frac{d q_{r i}}{d \mu} & =\frac{a_{i}-b c_{i}}{2(b c-\mu+2)^{\prime}} \\
\frac{d \pi_{0}^{r}}{d \mu} & =\frac{\sum_{i=1}^{n}\left(a_{i}-b c_{i}\right)^{2}}{8 b(b c-\mu+2)^{2}} \\
\frac{d \pi_{i}^{r}}{d \mu} & =\frac{\left(a_{i}-b c_{i}\right)^{2}}{4 b(b c-\mu+2)^{2}} \\
\frac{d \pi^{r}}{d \mu} & =\frac{3 \sum_{i=1}^{n}\left(a_{i}-b c_{i}\right)^{2}}{8 b(b c-\mu+2)^{2}} .
\end{aligned}
$$

Because $\forall i=1,2, \ldots, n$, we have $\mu \geq b c$ and $\sum_{i=1}^{n} a_{i}=a$. Therefore, we conclude that $\frac{d p_{r i}}{d \mu}<$ $0, \frac{d q_{r i}}{d \mu}>0, \frac{d \pi_{0}^{r}}{d \mu}>0, \frac{d \pi_{i}^{r}}{d \mu}>0, \frac{d \pi^{r}}{d \mu}>0$.

According to Theorem 2, the dominant-retailer can enhance its own competitiveness by implementing CSR. Because undertaking CSR can encourage consumers to buy more of the products, which reduces the retail price, the market demand and order quantities will increase, making the magnitude of increasing order quantities an increasing function so that the profits of the retailer will increase with the CSR coefficient. For the suppliers, undertaking CSR does not affect the supplier's wholesale price, but the market demand is positively related to the CSR coefficient. Therefore, the profits of the suppliers will increase with $\mu$, and so the profits of the whole supply chain are positively related to $\mu$.

\subsubsection{The Supply Chain Optimal Decision-Making When Only the Suppliers are CSR}

In a dominant-retailer supply chain with only the suppliers being CSR, assume that the retailer firstly determines its retail price and order quantity, and then the suppliers make their optimal decision based on the retailer's decision by employing the Stackelberg game. Assume that $p_{s i}, w_{s i}, q_{s i}, \pi_{0}^{s}, \pi_{i}^{s}, \pi^{s}$ stand for the retail price, wholesale price, order quantity, and the profit functions of the retailer, suppliers, and the whole supply chain, respectively. Then, we have:

$$
\begin{gathered}
\pi_{0}^{s}=\sum_{i-1}^{n}\left(p_{s i}-w_{s i}\right) q_{s i}, i=1, \ldots, n, \\
\pi_{i}^{s}=\left(\begin{array}{c}
\left.w_{s i}-c_{s i}\right) q_{s i}+\frac{\mu q_{s i}^{2}}{2 b}-\frac{c q_{s i}^{2}}{2}, i=1, \ldots, n \\
\text { s.t. }\left\{\begin{array}{c}
\mu A(q) \\
0<\mu<1
\end{array}\right. \\
\pi^{s}=\pi_{0}^{s}+\sum_{i=1}^{n} \pi_{i}^{s}, i=1, \ldots, n
\end{array}\right.
\end{gathered}
$$


Theorem 3. Let $p_{s i}^{*}, q_{s i}^{*}$, $w_{s i}^{*}$ be the optimal retail price, order quantity and wholesale price of the supply chain. Then, for $p_{s i}, w_{s i}, q_{s i}, \mu, a, b, c, a_{i}, c_{i}, \forall i=1,2, \ldots, n$, satisfying $\mu \geq b c$ and $\sum_{i=1}^{n} a_{i}=a$, if all the suppliers undertake CSR while the retailer does not, the following hold true:

$$
\begin{gathered}
p_{s i}^{*}=\frac{a_{i}(b c-\mu+3)+b c_{i}}{b(b c-\mu+4)}, \\
q_{s i}^{*}=\frac{a_{i}-b c_{i}}{b c-\mu+4}, \\
w_{s i}^{*}=\frac{a_{i}(b c-\mu+2)+2 b c_{i}}{b(b c-\mu+4)} .
\end{gathered}
$$

Proof. Differentiating Equation (22) with respect to variable $p_{s i}^{*}$ and equating the result to zero provide

$$
\frac{\partial \pi_{0}^{s}}{\partial p_{s i}}=\left(a_{i}-b p_{s i}\right)-b\left(p_{s i}-w_{s i}\right)=0, i=1,2, \ldots, n,
$$

which gives the retail price $p_{s i}=\frac{a_{i}+b w_{s i}}{2 b}$. By substituting $p_{s i}$ into the demand function $q_{s i}=a_{i}-$ $b p_{s i}, \sum_{i=1}^{n} a_{i}=a$, we obtain the order quantity $q_{s i}=\frac{a_{i}-b w_{s i}}{2}$. Then, by substituting what is just obtained into Equation (23) and differentiating Equation (23) with respect to variable $w_{s i}$, we have the following first order condition:

$$
\frac{\partial \pi_{i}^{s}}{\partial w_{s i}}=\frac{(b c-\mu+2)\left(a_{i}-b w_{s i}\right)+2 b\left(c_{i}-w_{s i}\right)}{4}=0
$$

from which we obtain the optimal wholesale price $w_{s i}^{*}=\frac{a_{i}(b c-\mu+2)+2 b c_{i}}{b(b c-\mu+4)}$. Similarly, from the expressions of the retail price and order quantity, the optimal retail price and order quantity can be acquired as follows:

$$
\begin{gathered}
p_{s i}^{*}=\frac{a_{i}(b c-\mu+3)+b c_{i}}{b(b c-\mu+4)}, \\
q_{s i}^{*}=\frac{a_{i}-b c_{i}}{b c-\mu+4} .
\end{gathered}
$$

Next, by using the optimal retail price $p_{s i}^{*}$, order quantity $q_{s i}^{*}$ and wholesale price $w_{s i}^{*}$, the profits of the retailer, suppliers, and the whole supply chain with only the suppliers being CSR can be acquired as follows:

$$
\begin{gathered}
\pi_{0}^{s *}=\frac{\sum_{i=1}^{n}\left(b c_{i}-a_{i}\right)^{2}}{b(b c-\mu+4)^{2}} \\
\pi_{i}^{s *}=\frac{\left(b c_{i}-a_{i}\right)^{2}}{2 b(b c-\mu+4)^{\prime}} \\
\pi^{s *}=\frac{(b c-\mu+6) \sum_{i=1}^{n}\left(b c_{i}-a_{i}\right)^{2}}{2 b(b c-\mu+4)^{2}} .
\end{gathered}
$$

Theorem 4. In the retailer-dominated supply chain with only the suppliers being CSR, the following hold true:

1. The wholesale price and the retailer price are negatively correlated with the CSR coefficient $\mu$;

2. The order quantity is positively related to the CSR coefficient $\mu$; and 
3. The profits of the supply chain members and the whole supply chain are positively correlated with the CSR coefficient $\mu$.

Proof. In order to explore the relationship between all the decision-making variables, mentioned in Theorem 4, and CSR, compute the partial derivatives of the retail price, order quantity, the profits of the supply chain members, and the entire supply chain with respect to the CSR coefficient $\mu$, from which we acquire the following:

$$
\begin{gathered}
\frac{d p_{s i}}{d \mu}=\frac{b c_{i}-a_{i}}{b(b c-\mu+4)}<0, \\
\frac{d w_{s i}}{d \mu}=\frac{2\left(b c_{i}-a_{i}\right)}{b(b c-\mu+4)^{2}}<0, \\
\frac{d q_{s i}}{d \mu}=\frac{a_{i}-b c_{i}}{(b c-\mu+4)^{2}}>0, \\
\frac{d \pi_{0}^{s}}{d \mu}=\frac{2 \sum_{i=1}^{n}\left(b c_{i}-a_{i}\right)^{2}}{b(b c-\mu+4)^{3}}>0, \\
\frac{d \pi_{i}^{s}}{d \mu}=\frac{\left(b c_{i}-a_{i}\right)^{2}}{2 b(b c-\mu+4)^{2}}>0, \\
\frac{d \pi^{s}}{d \mu}=\frac{(b c-\mu+8) \sum_{i=1}^{n}\left(b c_{i}-a_{i}\right)^{2}}{2 b(b c-\mu+4)^{3}}>0 .
\end{gathered}
$$

According to Theorem 4, the suppliers can reduce their wholesale price to promote their products with CSR properties accepted by consumers. Thus, the order quantity will increase, and the magnitude of increase of the wholesale price is a decreasing function, while the profits of the $n$ suppliers increase. For the retailer, because the wholesale price gets lower, it will choose to reduce the retail price in order to promote sales, but its magnitude of price reduction is lower than that of the increasing order quantity so that the profits of the retailer will increase with the CSR coefficient $\mu$, and the total profits of the supply chain also increase.

\subsection{A Supply Chain Decision-Making Mechanism under Centralized Decision-Making}

In today's society, the competition among enterprises is essentially competition among the supply chains behind the enterprises. To improve the profit margins and gain additional competitive advantages for the enterprises, cooperation is a popular and effective way. That is, all decision-makers make decisions based on maximizing system-wide profits instead of maximizing their own individual profits. In the centralized decision-making, the system-wide profit is the sum of the profits of all members in the decentralized decision-making scheme. For any supply chain, the questions we like to address are: What is the impact of whether undertaking CSR or not on the decision-making of the supply chain members and the overall profits of the entire supply chain? In addition, what are the characteristics of the relevant decision-making mechanism? To describe and deal with these problems, assume that $\pi^{N}, \pi$ stand for the overall profit of the supply chain either without considering or considering CSR, respectively. Based on the model assumptions and analysis, the expressions of these two quantities are respectively given as follows:

$$
\pi^{N}=\sum_{i=1}^{n}\left(p_{i}^{N}-w_{i}^{N}\right) q_{i}^{N}
$$




$$
\pi=\sum_{i=1}^{n}\left(p_{i}-w_{i}\right) q_{i}+\frac{(\mu-b c) \sum_{i=1}^{n} q_{i}^{2}}{2 b} .
$$

\subsubsection{The Supply-Chain's Optimal Decision-Making without Considering CSR}

For the retailer-dominated supply chain, if all members of the supply chain do not undertake their CSR under the centralized decision-making, there is no need for anyone to bear the cost of CSR. In this case, the supply-chain members adopt the strategy of cooperation to make their decisions from the overall profit of the supply chain.

Theorem 5. Assume that $p_{i}^{N *}, q_{i}^{N *}$ stand for the optimal retail price and order quantity of the supply chain without considering CSR in the centralized decision-making, respectively. Then, for $\mu, a, b, c, a_{i}, c_{i}, \forall i=$ $1,2, \ldots, n$, satisfying $\mu \geq b c$ and $\sum_{i=1}^{n} a_{i}=a$, the following hold true:

$$
\begin{aligned}
& p_{i}^{N *}=\frac{a_{i}+b c_{i}}{2 b}, \\
& q_{i}^{N *}=\frac{a_{i}-b c_{i}}{2} .
\end{aligned}
$$

Proof. Differentiating Equation (37) with respect to variable $p_{i}^{N}$ and equating the result to zero provide

$$
\frac{\partial \pi}{\partial p_{i}^{N}}=\left(a_{i}-b p_{i}\right)-b\left(p_{i}^{N}-c_{i}\right)=0,
$$

from which we obtain the optimal retail price $p_{i}^{N *}=\frac{a_{i}+b c_{i}}{2 b}$, and then the optimal order quantity $q_{i}^{N *}=\frac{a_{i}-b c_{i}}{2}$ by substituting $p_{i}^{N *}$ into the demand function.

According to the expressions of the optimal retail price and order quantity in Theorem 5 , the profits of the supply chain $\pi^{N *}$ can be obtained as follows:

$$
\pi^{N *}=\frac{\sum_{i=1}^{n}\left(a_{i}-b c_{i}\right)^{2}}{4 b} .
$$

\subsubsection{The Supply Chain Optimal Decision-Making Considering CSR}

For the retailer-dominated supply chain, if all members undertake their CSR under the centralized decision-making, then there exist the corresponding CSR costs that might affect the profits of the overall supply chain and the supply-chain members. Nonetheless, for the sake of producing more profits, the supply chain members adopt the strategy of cooperation in their decision-making.

Theorem 6. Assume that $p_{i}^{*}, q_{i}^{*}$ stand for the optimal retail price and order quantity of the supply chain considering CSR under the centralized decision-making. Then, for $\mu, a, b, c, a_{i}, c_{i}, \forall i=1,2, \ldots, n$, satisfying $\mu \geq b c$ and $\sum_{i=1}^{n} a_{i}=a$, the following hold true:

$$
\begin{gathered}
p_{i}^{*}=\frac{a_{i}(b c-\mu+1)+b c_{i}}{b(b c-\mu+2)}, \\
q_{i}^{*}=\frac{a_{i}-b c_{i}}{b c-\mu+2} .
\end{gathered}
$$


Proof. All details are similar to those of Theorem 5 and are omitted.

Based on the expressions of the optimal retail price and order quantity in Theorem 6, the profits of the whole supply chain $\pi^{*}$ can be obtained as follows:

$$
\pi^{*}=\frac{\sum_{i=1}^{n}\left(a_{i}-b c_{i}\right)^{2}}{2 b(b c-\mu+2)}
$$

According to the overall profits of the supply chain under either the decentralized or centralized decision-making, the following result can be obtained.

Theorem 7. For any $\mu, a, b, c, a_{i}, c_{i}, \forall i=1,2, \ldots, n$, satisfying $\mu \geq b c$ and $\sum_{i=1}^{n} a_{i}=a$, undertaking CSR can provide better performance for the whole supply chain under the centralized decision-making.

Proof. For $b c \leq \mu \leq 1$, we have the following:

$$
\begin{gathered}
\pi-\pi^{r}=\frac{\sum_{i=1}^{n}\left(a_{i}-b c_{i}\right)^{2}}{2 b(b c-\mu+2)}-\frac{3 \sum_{i=1}^{n}\left(b c_{i}-a_{i}\right)^{2}}{8 b(b c-\mu+2)}=\frac{\sum_{i=1}^{n}\left(b c_{i}-a_{i}\right)^{2}}{8 b(b c-\mu+2)}>0, \\
\pi-\pi^{s}=\frac{\sum_{i=1}^{n}\left(b c_{i}-a_{i}\right)^{2}}{2 b(b c-\mu+2)}-\frac{(b c-\mu+6) \sum_{i=1}^{n}\left(b c_{i}-a_{i}\right)^{2}}{2 b(b c-\mu+4)^{2}}=\frac{2 \sum_{i=1}^{n}\left(b c_{i}-a_{i}\right)^{2}}{b(b c-\mu+2)(b c-\mu+4)^{2}}>0, \\
\pi-\pi^{N}=\frac{\sum_{i=1}^{n}\left(a_{i}-b c_{i}\right)^{2}}{2 b(b c-\mu+2)}-\frac{\sum_{i=1}^{n}\left(a_{i}-b c_{i}\right)^{2}}{4 b}=\frac{(\mu-b c) \sum_{i=1}^{n}\left(a_{i}-b c_{i}\right)^{2}}{4 b(b c-\mu+2)}>0 .
\end{gathered}
$$

That is, $\pi>\pi^{r}, \pi>\pi^{s}, \pi>\pi^{N}$.

According to Theorem 7, it can be seen that the total profits of the supply chain with CSR are higher than those of the supply chain without CSR under the centralized decision-making scheme, and higher than those of the supply chain with the retailer or suppliers all undertaking CSR under the decentralized decision-making scheme, respectively. These results show that it is very necessary for the supply chain members to undertake CSR, and that, in such a case, there exist a double marginal effect and the further Pareto improvement of the supply chain performance.

\section{A Supply Chain Coordination Decision-Making Mechanism Based on Cost Sharing of CSR}

According to the above analysis, undertaking CSR can encourage consumers to buy more products, reduce the retail prices, and increase the market demand, while the profits of the retail, the suppliers, and the whole supply chain will increase. However, undertaking CSR requires paying a certain cost (such as personnel training, supervision, emission reduction, waste disposal, and other costs). In a retailer-dominant supply chain with CSR, the suppliers lie in a subordinate position with the retailer in a dominant position, while they pursue the maximization of their respective profits. In order to ensure the long-term relationship with the suppliers and maximize the profits of the whole supply chain, the retailer can take advantage of its information asymmetry and bargaining power to coordinate the suppliers to practice CSR by sharing partial CSR of suppliers (for example, how to make suppliers understand the business value of CSR, how to reflect the return of inputs, and provide opportunities for suppliers to build capacity to achieve sustainable business cooperation, rather than simply monitoring from the perspective of supervision), so that a super conflict equilibrium between Nash and Shapely equilibrium is generated among the retailer and $n$ suppliers [52]. Therefore, the retailer should design 
a reasonable coordination decision-making mechanism with the super conflict equilibrium in order to coordinate and motivate suppliers to take more CSR and ensure the stability of the supply chain.

In the retailer-dominant supply chain considering CSR, based on the Stackelberg game, being the leader, the dominant retailer possesses the advance of determining the retail price, the order quantity, the proportion of cost sharing rate, and the consumer surplus sharing rate, while the suppliers determine their own wholesale prices according to the retailer's decision-making. Assume that $p_{h i}, q_{h i}, w_{h i}, c_{i}$ stand for the retail price, order quantity, wholesale price, and unit cost of supplier $i$, respectively; $\lambda_{i}, \varphi_{i}$ express the proportion of CSR cost sharing and cumulative consumer surplus by the retailer, respectively, with $\left(1-\lambda_{i}\right),\left(1-\varphi_{i}\right)$ representing the proportion of CSR cost sharing and cumulative consumer surplus of supplier $i$, respectively. Here, for convenient calculation, we let $\varphi_{i}=\lambda_{i}, \lambda_{i}=\lambda$, i.e., there is no consideration for the importance of different suppliers to ensure the fairness between different suppliers. In order to ensure that the suppliers consciously cooperate with the retailer, the retailer needs to make sure that the profits of the supply chain members and the whole supply chain are not less than the levels desired prior to the coordination. Assume that $\pi_{0}^{h}, \pi_{i}^{h}, \pi^{h}$ stand for the profits of the retailer, supplier $i$, and the whole supply chain, respectively. Then, they can be written as follows:

$$
\begin{aligned}
& \pi_{0}^{h}=\sum_{i=1}^{n}\left(p_{h i}-w_{h i}\right) q_{h i}+\frac{1}{2 b}(\mu-b c)(1+\lambda)\left(\sum_{i=1}^{n} q_{h i}^{2}\right) \\
& \left\{\begin{array}{c}
\mu A \geq C\left(q_{h}\right) \\
0<\lambda<1 \\
0<\mu<1 \\
\pi_{0}^{h} \geq \max \left(\pi_{0}^{r}, \pi_{0}^{s}\right)
\end{array},\right. \\
& \begin{array}{l}
\pi_{i}^{h}=\left(w_{h i}-c_{i}\right) q_{h i}+\frac{1}{2 b}(\mu-b c)(1-\lambda) q_{h i}^{2} \\
\left\{\begin{array}{c}
\mu A \geq C\left(q_{h}\right) \\
0<\lambda<1 \\
0<\mu<1 \\
\pi_{i}^{h} \geq \max \left(\pi_{i}^{r}, \pi_{i}^{s}\right)
\end{array}\right.
\end{array} \\
& \pi^{h}=\pi_{0}^{h}+\sum_{i=1}^{n} \pi_{i}^{h} \\
& \text { s.t. }\left\{\pi^{h} \geq \max \left(\pi^{r}, \pi^{s}\right)\right.
\end{aligned}
$$

Theorem 8. Let $B=4-(\lambda+3)(\mu-b c), A_{i}=\frac{\left(a_{i}-b c_{i}\right)^{2}}{B^{2}}$, for $\forall i=1,2, \ldots, n, \varphi, \lambda, \mu \in(0,1)$, satisfying $\mu \geq b c, \sum_{i=1}^{n} a_{i}=a$. If $p_{h i}^{*}, q_{h i}^{*}, w_{h i}^{*}$ stand for the optimal retail price, order quantity and wholesale price under the centralized decision-making scheme, respectively, then the following hold true:

$$
\begin{gathered}
p_{h i}^{*}=\frac{a_{i} B-a_{i}+b c_{i}}{b B}, \\
q_{h i}^{*}=\frac{a_{i}-b c_{i}}{B} \\
w_{h i}^{*}=\frac{2\left(a_{i}+b c_{i}\right)-(\mu-b c)\left[2 a_{i}+(1+\lambda) b c_{i}\right]}{b B} .
\end{gathered}
$$


Proof. For $\forall i=1,2, \ldots, n, \varphi, \lambda, \mu \in(0,1)$, let $B=4-(\lambda+3)(\mu-b c)$, and $A_{i}=\frac{\left(a_{i}-b c_{i}\right)^{2}}{B^{2}}$. Differentiating Equation (48) with respect to $p_{h i}$ and setting the result to 0 lead to:

$$
\frac{\partial \pi_{0}^{h}}{\partial p_{h i}}=[1-(1+\lambda)(\mu-b c)]\left(a_{i}-b p_{h i}\right)-b\left(p_{h i}-w_{h i}\right)=0
$$

from which the retail price $p_{h i}=\frac{\left(a_{i}+b w_{h i}\right)-a_{i}(1+\lambda)(\mu-b c)}{b[2-(1+\lambda)(\mu-b c)]}$ is obtained, and then the order quantity $q_{h i}=\frac{a_{i}-b w_{h i}}{2-(1+\lambda)(\mu-b c)}$ is determined by replacing $q_{h i}=a_{i}-b p_{h i}, \sum_{i=1}^{n} a_{i}=a$ into the expression of the retail price solved above.

Substituting $p_{h i}$ and $q_{h i}$ into Equation (49), differentiating Equation (49) with respect to $w_{c i}$, and equating the result to 0 provide:

$$
\frac{\partial \pi_{s i}^{h}}{\partial w_{h i}}=\frac{(\mu-b c)\left[(\lambda+3) b w_{h i}-(\lambda+1) b c_{i}-2 a_{i}\right]+2\left(a_{i}+b c_{i}\right)-4 b w_{h i}}{[2-(1+\lambda)(\mu-b c)]^{2}}=0
$$

from which the optimal wholesale price, retailer price, and order quantity can be obtained.

Assume that $\pi_{0}^{h *}, \pi_{i}^{h *}, \pi^{h *}$ stand for the profits of the retailer, supplier $i$, and the whole supply chain under the coordination mechanism with CSR, respectively. Then, from Theorem 8 and Equations (48)-(50), the profits of the retailer, suppliers and the whole supply chain can be obtained, respectively, as follows:

$$
\begin{gathered}
\pi_{0}^{h *}=\frac{(1+\lambda)(\mu-b c)-2}{2 b} \sum_{i=1}^{n} A_{i}, \\
\pi_{i}^{h *}=\frac{\left(a_{i}-b c_{i}\right)^{2}}{2 b B}, \\
\pi^{h *}=\pi_{0}^{h *}+\sum_{i=1}^{n} \pi_{i}^{h *},
\end{gathered}
$$

where $\mu \geq b c, 0<\varphi<1,0<\lambda<1,0<\mu<1, i=1, \ldots, n, A_{i}=\frac{\left(a_{i}-b c_{i}\right)^{2}}{B^{2}}$, and $B=4-(\lambda+3)(\mu-b c)$.

To ensure the maximization of profits for the whole supply chain and the supplying members are not destroyed, it is necessary to design a reasonable cost sharing proportion of CSR so that an effective supply chain coordination mechanism with CSR can be established. Correspondingly, the following Theorem 9 can be established.

Theorem 9. Under this cost-sharing mechanism, when the sharing proportion satisfies $0<\lambda<\frac{1-(\mu-b c)}{\mu-b c}$, where $\frac{1-(\mu-b c)}{\mu-b c} \leq 1$, the coordination decision-making mechanism based on cost sharing of CSR can achieve the Pareto optimality.

Proof. For the retailer-dominated supply chain considering CSR, the retailer should ensure that the pure profits are not less than zero and the total profits of the supply chain members are not less than those of pre-coordination to effectively coordinate the supply chain with CSR under the centralized decision-making scheme, that is, $\pi_{0}^{h} \geq \max \left(\pi_{r}^{r}, \pi_{r}^{S}\right), \pi_{i}^{h} \geq \max \left(\pi_{i}^{r}, \pi_{i}^{S}\right), p_{i}^{h}>w_{i}^{h}$ and $w_{i}^{h}>c_{i}$.

According to the profits of the retailer and suppliers under the decentralized, centralized and coordination decision-making schemes, it can easily be found that the coordinated decision-making mechanism based on cost sharing of CSR satisfies the following:

$$
\frac{(1+\lambda)(\mu-b c)-2}{2 b[4-(\lambda+3)(\mu-b c)]} \geq \max \left\{\frac{1}{8 b(c+2)}, \frac{1}{b(b c-\mu+4)^{2}}\right\}
$$




$$
\begin{gathered}
\frac{1}{2 b[4-(\lambda+3)(\mu-b c)]} \geq \max \left\{\frac{1}{4 b(b c-\mu+2)}, \frac{1}{2 b(b c-\mu+4)}\right\}, \\
\frac{a_{i} B-a_{i}+b c_{i}}{b B}>\frac{2\left(a_{i}+b c_{i}\right)-(\mu-b c)\left[2 a_{i}+(1+\lambda) b c_{i}\right]}{b B}, \\
\frac{2\left(a_{i}+b c_{i}\right)-(\mu-b c)\left[2 a_{i}+(1+\lambda) b c_{i}\right]}{b B}>c_{i},
\end{gathered}
$$

from which the optimal range of cost-sharing proportion can be obtained i.e., only $\frac{1-(\mu-b c)}{\mu-b c} \leq 1$, $0<\lambda<\frac{1-(\mu-b c)}{\mu-b c}$, if not, $0<\lambda<1$ should be satisfied.

Theorem 10. In the retailer-dominated supply chain considering CSR, the following hold true:

1. The wholesale price and the retailer price are negatively correlated to the CSR coefficient $\mu$;

2. The order quantity is positively correlated to the CSR coefficient $\mu$; and

3. The profits of the supply chain members and the whole supply chain are positively correlated with the CSR coefficient $\mu$.

Proof. In order to ensure the effectiveness of the supply chain coordination decision-making mechanism based on cost sharing of CSR, and obtain the relationship between these decision variables, the profits of the supply chain members and the whole supply chain, and CSR, for $\forall i=1,2, \ldots, n$, $\varphi, \lambda, \mu \in(0,1)$, satisfying $\mu \geq b c$ and $\sum_{i=1}^{n} a_{i}=a$, differentiating the retail price, order quantity, the profits of the supply chain members and the whole supply chain with respect to the CSR coefficient $\mu$ provides:

$$
\begin{gathered}
\frac{d p_{h i}}{d \mu}=-\frac{(\lambda+3)\left(a_{i}-b c_{i}\right)}{b B^{2}}<0, \\
\frac{d q_{h i}}{d \mu}=\frac{(\lambda+3)\left(a_{i}-b c_{i}\right)}{B^{2}}>0, \\
\frac{d w_{h i}}{d \mu}=\frac{2 n \lambda\left(b c_{i}-a_{i}\right)}{b k^{2}}<0, \\
\frac{d \pi_{0}^{h}}{d \mu}=-\frac{8-(\mu-b c)\left(\lambda^{2}+4 \lambda+3\right)}{2 b B} \sum_{i=1}^{n} A_{i}>0, \\
\frac{d \pi_{i}^{h}}{d \mu}=\frac{(\lambda+3)\left(a_{i}-b c_{i}\right)^{2}}{2 b B^{2}}>0, \\
\frac{d \pi^{h}}{d \mu}=\frac{d \pi_{0}^{h}}{d \mu}+\frac{d \pi_{i}^{h}}{d \mu}>0 .
\end{gathered}
$$

From Theorems 2, 4, 7, and 10, one can see the following results:

(1) The optional retailer price and wholesale price are negatively correlated with the CSR coefficient $\mu$, but the optimal order quantity is positively correlated to the CSR coefficient $\mu$ when only the retailer is CSR. The optimal order quantity has nothing to do with the CSR coefficient $\mu$ under the decentralized decision-making scheme with only the suppliers being CSR.

(2) No matter if the retailer or the suppliers undertake CSR or not, the profits of the supply chain members and the total profits of the supply chain increase with the CSR coefficient. 


\section{Numerical Illustration}

With the rapid development of information technology and economy, more and more people have been focusing on their demand with high quality and convenience. This has made the retail industry develop rapidly, causing some larger retailers, such as Wal-Mart, Carrefour, Suning (https: //www.suning.com/), Auchan (www.auchan.com.cn/), GOME (https:/ /www.gome.com.cn/), etc., to arise. Their appearances result in changes of the power structure in the supply chain, in which the retailers dominate over their suppliers. Generally speaking, the suppliers create greater pollution to the environment because of their manufacturing of products, while the retailers create less in the retailer-dominated supply chain. However, neither the retailers nor the suppliers are willing to undertake CSR alone. In order to mobilize the enthusiasm of the supply chain members and improve the levels of profits of the whole supply chain, it is necessary for a reasonable supply chain coordination mechanism with embedded CSR components to be designed. Based on the previously proposed coordination mechanism with a CSR component based on cost sharing, let us take a supply chain of refrigerators dominated by the retailer as an example to conduct our analysis. In this particular supply chain, there exist three refrigerator suppliers and a retailer (like GOME, a Chinese firm). In order to explore the effects of CSR on decision variables and validate these decision making mechanism proposed in this paper, we present a numerical example by considering the parameter value as:

$$
a=100, a_{1}=20, a_{2}=30, a_{3}=50 ; c_{1}=5, c_{2}=3, c_{3}=2 ; b=0.2 ; c=1 ; \mu=0.5 ; 0<\lambda<1 .
$$

Based on the previously proposed models under either the decentralized or centralized decision-making scheme with CSR, we apply Maple 18.0 to calculate the profits of the supply chain members (the retailer and the suppliers) and the whole supply chain, respectively, and the results are shown in Table 1.

Table 1. The profits of the supply chain and its members under either the decentralized or centralized decision-making scheme (unit: 10,000 RMB Yuan).

\begin{tabular}{ccccc}
\hline & \multicolumn{2}{c}{ Decentralized Decision-Making } & \multicolumn{2}{c}{ Centralized Decision-Making } \\
\hline & $\begin{array}{c}\text { Only the Retailer } \\
\text { is CSR }\end{array}$ & $\begin{array}{c}\text { Only the } \\
\text { Suppliers is CSR }\end{array}$ & $\begin{array}{c}\text { Without } \\
\text { Considering CSR }\end{array}$ & Considering CSR \\
\hline$\pi_{0}$ & 1354.97 & 1346.06 & - & - \\
$\pi_{1}$ & 265.44 & 243.91 & - & - \\
$\pi_{2}$ & 635.56 & 584.03 & - & - \\
$\pi_{3}$ & 1808.94 & 1662.27 & - & - \\
$\pi$ & 4064.91 & 3836.28 & 4606.90 & 5419.88 \\
\hline
\end{tabular}

As can be seen from Table 1, the profits of the supply chain and its members when only the retailer is CSR are greater than those when only the suppliers are CSR; and the total profit obtained by considering CSR is greater than that by not considering CSR under the centralized decision-making scheme. In addition, no matter if CSR is considered or not, the total profit of the supply chain under the centralized decision-making scheme is greater than that under the decentralized decision-making scheme. These results indicate that it is necessary to be CSR and, in such a case, there is Pareto improvement in the supply-chain's performance. This end is consistent with Theorem 7.

\subsection{Effects of CSR on Decision Variables}

How the CSR coefficient $\mu$ affects the supply chain decision-making plays an important guidance role in the CSR implementation of the decision-makers. Recall that, in this study, we take $\mu$ to be $0.1,0.2,0.3,0.4,0.5,0.6,0.7,0.8$, and 0.9 to analyze the optimal decision-making for the following three cases: the decentralized, centralized, and coordination decision-making, respectively. In the supply chain, because CSR has the same effect on all of the suppliers, let us choose one 
supplier along with the retailer in the analysis of the influence of the CSR coefficients $\mu$ on the supply chain decision-making. According to the collected data, we take the parameter values as $n=1, a_{1}=20, c_{1}=5, b=0.2, \mathrm{c}=1, \lambda=0.5$, and then calculate the influence of the optimal decision-making and the profits of the supply chain members with different CSR coefficients under the decentralized, centralized decision-making scheme, and cost sharing by using the previously proposed models, respectively. The results are shown in Tables 2 and 3, respectively. From these tables, we can draw the trend lines of the decision-making variables and the profits of the supply chain members with the changing CSR coefficient $\mu$ under the assumptions that only the retailer is CSR, or only the suppliers are CSR, or all members of the supply chain are CSR. See Figures 1-3 for details.

Table 2. The optimal decision-making and the profits of the supply chain members with different CSR coefficients under the decentralized decision-making scheme.

\begin{tabular}{ccccccccccc}
\hline & \multicolumn{4}{c}{ Only the Retailer is CSR } & \multicolumn{4}{c}{ Only the Suppliers are CSR } \\
\cline { 2 - 11 } & $\boldsymbol{p}$ & $\boldsymbol{w}$ & $\boldsymbol{q}$ & $\boldsymbol{\pi}_{\mathbf{0}}$ & $\boldsymbol{\pi}_{\boldsymbol{i}}$ & $\boldsymbol{p}$ & $\boldsymbol{w}$ & $\boldsymbol{q}$ & $\boldsymbol{\pi}_{\mathbf{0}}$ & $\boldsymbol{\pi}_{\boldsymbol{i}}$ \\
\hline 0.1 & 77.38 & 52.50 & 4.52 & 107.44 & 214.88 & 76.83 & 53.66 & 4.64 & 107.38 & 220.12 \\
0.2 & 76.25 & 52.50 & 4.75 & 112.81 & 225.63 & 76.25 & 52.50 & 4.75 & 112.81 & 225.63 \\
0.3 & 75.00 & 52.50 & 5.00 & 118.75 & 237.5 & 75.64 & 51.28 & 4.87 & 118.67 & 231.41 \\
0.4 & 73.61 & 52.50 & 5.28 & 125.35 & 250.69 & 75.00 & 50.00 & 5.00 & 125.00 & 237.50 \\
0.5 & 72.05 & 52.50 & 5.59 & 132.72 & 265.44 & 74.32 & 48.65 & 5.14 & 131.85 & 243.92 \\
0.6 & 70.31 & 52.50 & 5.94 & 141.02 & 282.03 & 73.61 & 47.22 & 5.28 & 139.27 & 250.69 \\
0.7 & 68.33 & 52.50 & 6.33 & 150.42 & 300.83 & 72.86 & 45.71 & 5.43 & 147.35 & 257.86 \\
0.8 & 66.07 & 52.50 & 6.79 & 161.16 & 322.32 & 72.06 & 44.12 & 5.59 & 156.14 & 265.44 \\
0.9 & 63.46 & 52.50 & 7.31 & 173.56 & 347.12 & 71.21 & 42.42 & 5.75 & 165.75 & 273.49 \\
\hline
\end{tabular}

Table 3. The optimal decision-making and the profits of the supply chain members with different CSR coefficients under cost sharing of CSR.

\begin{tabular}{cccccc}
\hline $\boldsymbol{\mu}$ & $\boldsymbol{p}$ & $\boldsymbol{w}$ & $\boldsymbol{q}$ & $\boldsymbol{\pi}_{\mathbf{0}}$ & $\boldsymbol{\pi}_{\boldsymbol{i}}$ \\
\hline 0.1 & 78.76 & 53.05 & 4.37 & 102.54 & 207.47 \\
0.2 & 76.25 & 52.50 & 4.75 & 112.81 & 225.63 \\
0.3 & 73.97 & 51.85 & 5.21 & 125.32 & 247.26 \\
0.4 & 71.21 & 51.06 & 5.76 & 140.89 & 273.48 \\
0.5 & 67.80 & 50.08 & 6.44 & 160.74 & 305.93 \\
0.6 & 63.46 & 48.85 & 7.31 & 186.91 & 347.12 \\
0.7 & 57.78 & 47.22 & 8.44 & 222.81 & 401.11 \\
0.8 & 50.00 & 45.00 & 10.00 & 275.00 & 475.00 \\
0.9 & 38.71 & 41.78 & 12.26 & 356.87 & 582.26 \\
\hline
\end{tabular}



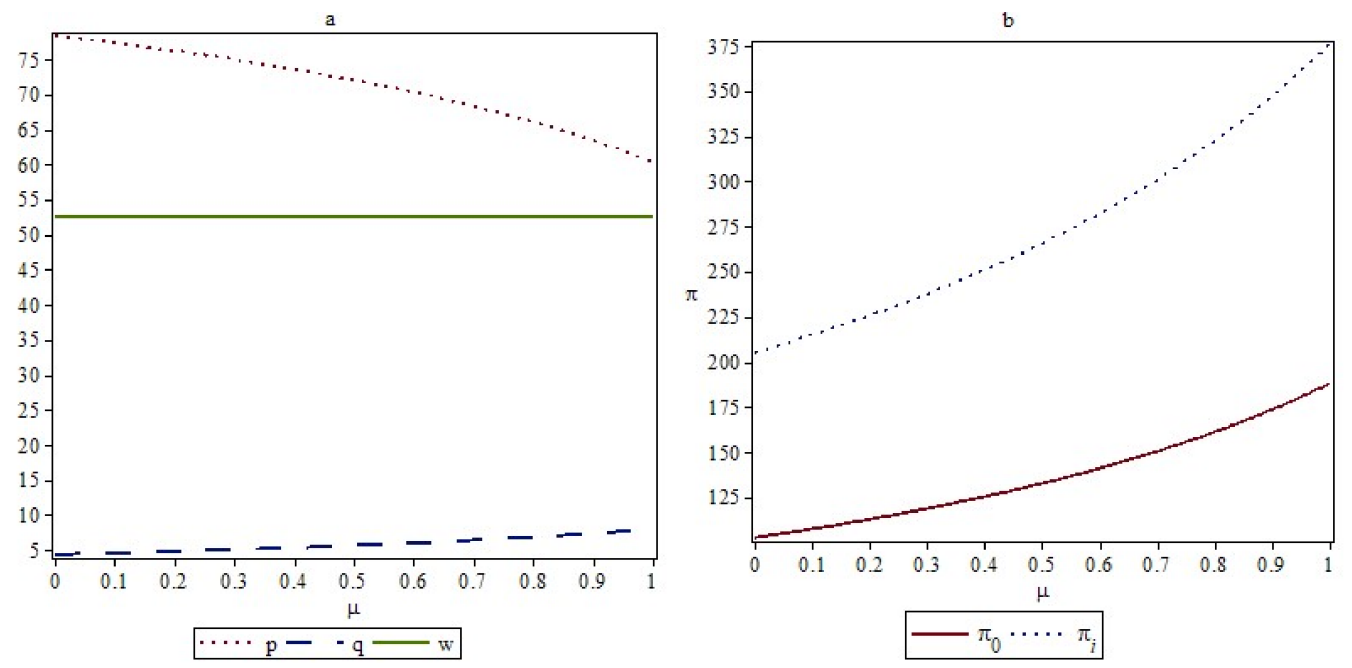

Figure 1. (a) decision-making variables with different CSR coefficients when only the retailer is CSR; (b) the profits of the supply chain members with different CSR coefficients when only the retailer is CSR.
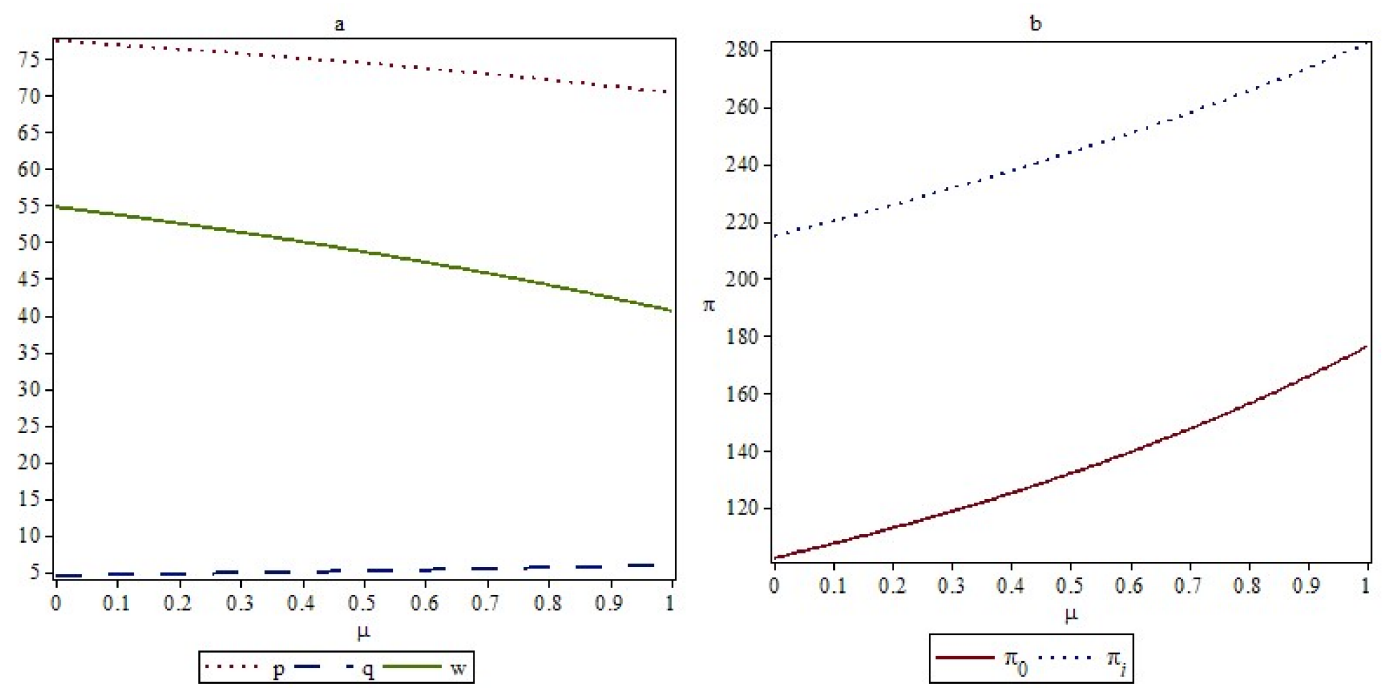

Figure 2. (a) decision-making variables with different CSR coefficients when only the suppliers are CSR; (b) the profits of the supply chain members with different CSR coefficients when only the suppliers are CSR. 

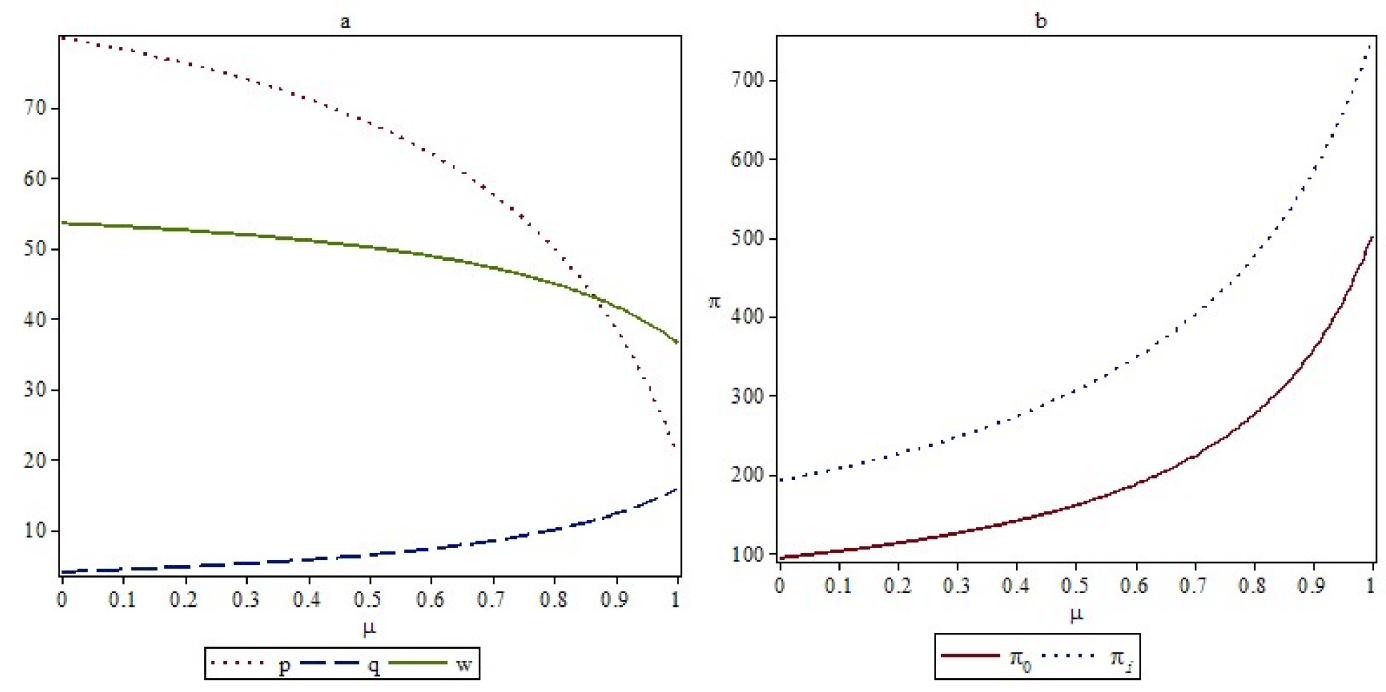

Figure 3. (a) decision-making variables with different CSR coefficients when the cost of CSR is shared; (b) the profits of the supply chain members with different CSR coefficients when the cost of CSR is shared.

According to Tables 2 and 3 and Figures 1 and 2, for the supply chain with CSR, no matter whether its members undertake CSR alone or jointly, the optimal retailer price and wholesale price are decreasing functions of the CSR coefficient, that is, they are negatively correlated with the CSR coefficient $\mu$. This shows that the higher the level undertaking CSR is, the lower the optimal price and the wholesale price. The optimal order quantity and the profits of the supply chain and its members are positively correlated with the CSR coefficient, which means that undertaking CSR could increase the order quantity, and the profits of the supply chain and its members. The more CSR is undertaken, the more the optimal order quantity and the profits will be. These results are consistent with Theorems 2,4 , and 7 . The specific analysis is as follows.

In Table 2, in the horizontal comparison, for the retailer, its profit under considering CSR is higher than that of considering no-CSR; for suppliers, its profit under considering CSR is lower than that of considering no-CSR, which means that suppliers prefer the retailer to exhibit CSR practice. In the vertical comparison, no matter who is socially responsible, the profits of all the members increase with the increasing of CSR level. It can be known by combining the horizontal comparison results that the pure profits of suppliers are decreasing and the consumer surplus cannot compensate its loss of shareholders' value, which means they are not willing to exhibit CSR practice in real operations.

In Figure 1, when the retailer increases CSR, the wholesale prices remain unchanged, and the selling prices are inversely proportional to its own CSR level. In addition, its order quantities and total profits are directly proportional to the CSR level, which explains its consumer surplus overcompensating for the loss of its pure profit. In Figure 2, when suppliers increase CSR, the wholesale prices decrease. In response, the retailer provides more effort to decrease the selling price in order to encourage the customers to buy more, which show the socially responsible SC performs more competitively than a traditional pure profit maximizing channel.

In Figure 3, we notice that the selling prices decrease with the increasing of the CSR level and is lower than the wholesale prices above a threshold of CSR (the same as the wholesale prices), which might result in negative pure profit, even if it helps to sell additional products and bring more orders from suppliers, and, as a consequence, the profits of the retailer and suppliers are win-win. However, the dominant retailer should control its intensity of CSR practices and set an appropriate code of conduct for suppliers to avoid the loss of profits to their shareholders. 


\subsection{Analysis of the Effectiveness of the Mechanism}

In order to analyze the effectiveness of our proposed mechanism based on CSR cost sharing, we compare the impacts of the different proportions of cost sharing on the supply chain by taking the CSR coefficient $\mu$ as 0.5 . If the proportions of cost sharing are selected as $0<\lambda<1$, respectively, then the profits of the supply-chain members under the decentralized and coordination decision-making schemes with cost sharing can be calculated by taking the parameter values as $a=100, a_{1}=20, a_{2}=$ $30, a_{3}=50 ; c_{1}=5, c_{2}=3, c_{3}=2 ; b=0.2 ; c=1$, and $0<\lambda<1$, and then they are used to identify the coordination effect by comparing their values. Considering the fact that the profits of GOME and its three refrigerator suppliers are not affected by the proportion of cost sharing under the decentralized decision-making scheme either when only the retailer is CSR or only the suppliers are CSR, the profits of the supply-chain members should be the same under different parameter values of $\lambda$. For the case of coordination decision-making with cost sharing, because the retailer and the suppliers share the cost of CSR, the profits of GOME, its three refrigerator suppliers, and the whole supply chain are affected by the proportion of cost sharing. The relevant calculation results are shown in Tables 4 and 5 and Figure 4.

Table 4. The profit of the supply chain members under decentralized decision-making.

\begin{tabular}{ccccccccccc}
\hline & \multicolumn{4}{c}{ Only the Retailer is CSR } & \multicolumn{4}{c}{ Only the Suppliers are CSR } \\
\cline { 2 - 11 } & $\pi_{\mathbf{0}}^{r}$ & $\pi_{\mathbf{1}}^{r}$ & $\boldsymbol{\pi}_{\mathbf{2}}^{r}$ & $\boldsymbol{\pi}_{\mathbf{3}}^{\boldsymbol{r}}$ & $\boldsymbol{\pi}^{\boldsymbol{r}}$ & $\boldsymbol{\pi}_{\mathbf{0}}^{\boldsymbol{r}}$ & $\boldsymbol{\pi}_{\mathbf{1}}^{\boldsymbol{r}}$ & $\boldsymbol{\pi}_{\mathbf{2}}^{\boldsymbol{r}}$ & $\boldsymbol{\pi}_{\mathbf{3}}^{\boldsymbol{r}}$ & $\boldsymbol{\pi}^{\boldsymbol{s}}$ \\
\hline 0.1 & 1354.97 & 265.44 & 635.55 & 1808.94 & 4064.91 & 1346.06 & 243.91 & 584.02 & 1662.27 & 3836.27 \\
0.2 & 1354.97 & 265.44 & 635.55 & 1808.94 & 4064.91 & 1346.06 & 243.91 & 584.02 & 1662.27 & 3836.27 \\
0.3 & 1354.97 & 265.44 & 635.55 & 1808.94 & 4064.91 & 1346.06 & 243.91 & 584.02 & 1662.27 & 3836.27 \\
0.4 & 1354.97 & 265.44 & 635.55 & 1808.94 & 4064.91 & 1346.06 & 243.91 & 584.02 & 1662.27 & 3836.27 \\
0.5 & 1354.97 & 265.44 & 635.55 & 1808.94 & 4064.91 & 1346.06 & 243.91 & 584.02 & 1662.27 & 3836.27 \\
0.6 & 1354.97 & 265.44 & 635.55 & 1808.94 & 4064.91 & 1346.06 & 243.91 & 584.02 & 1662.27 & 3836.27 \\
0.7 & 1354.97 & 265.44 & 635.55 & 1808.94 & 4064.91 & 1346.06 & 243.91 & 584.02 & 1662.27 & 3836.27 \\
0.8 & 1354.97 & 265.44 & 635.55 & 1808.94 & 4064.91 & 1346.06 & 243.91 & 584.02 & 1662.27 & 3836.27 \\
0.9 & 1354.97 & 265.44 & 635.55 & 1808.94 & 4064.91 & 1346.06 & 243.91 & 584.02 & 1662.27 & 3836.27 \\
1.0 & 1354.97 & 265.44 & 635.55 & 1808.94 & 4064.91 & 1346.06 & 243.91 & 584.02 & 1662.27 & 3836.27 \\
\hline
\end{tabular}

Table 5. The profit of the supply chain members under coordinated decision-making.

\begin{tabular}{cccccc}
\hline$\lambda$ & $\pi_{\mathbf{0}}^{h}$ & $\pi_{\mathbf{1}}^{h}$ & $\pi_{\mathbf{2}}^{h}$ & $\pi_{\mathbf{3}}^{h}$ & $\pi^{h}$ \\
\hline 0.1 & 1632.59 & 293.97 & 703.87 & 2003.38 & 4633.83 \\
0.2 & 1635.06 & 296.87 & 710.82 & 2023.16 & 4665.92 \\
0.3 & 1637.31 & 299.83 & 717.91 & 2043.32 & 4698.37 \\
0.4 & 1639.31 & 302.85 & 725.13 & 2063.89 & 4731.20 \\
0.5 & 1641.06 & 305.93 & 732.51 & 2084.89 & 4764.39 \\
0.6 & 1642.54 & 309.08 & 740.03 & 2106.30 & 4797.95 \\
0.7 & 1643.72 & 312.28 & 747.71 & 2128.16 & 4831.89 \\
0.8 & 1644.59 & 315.56 & 755.56 & 2150.49 & 4866.21 \\
0.9 & 1645.14 & 318.90 & 763.57 & 2173.28 & 4900.90 \\
1.0 & 1645.32 & 322.32 & 771.75 & 2196.57 & 4935.96 \\
\hline
\end{tabular}




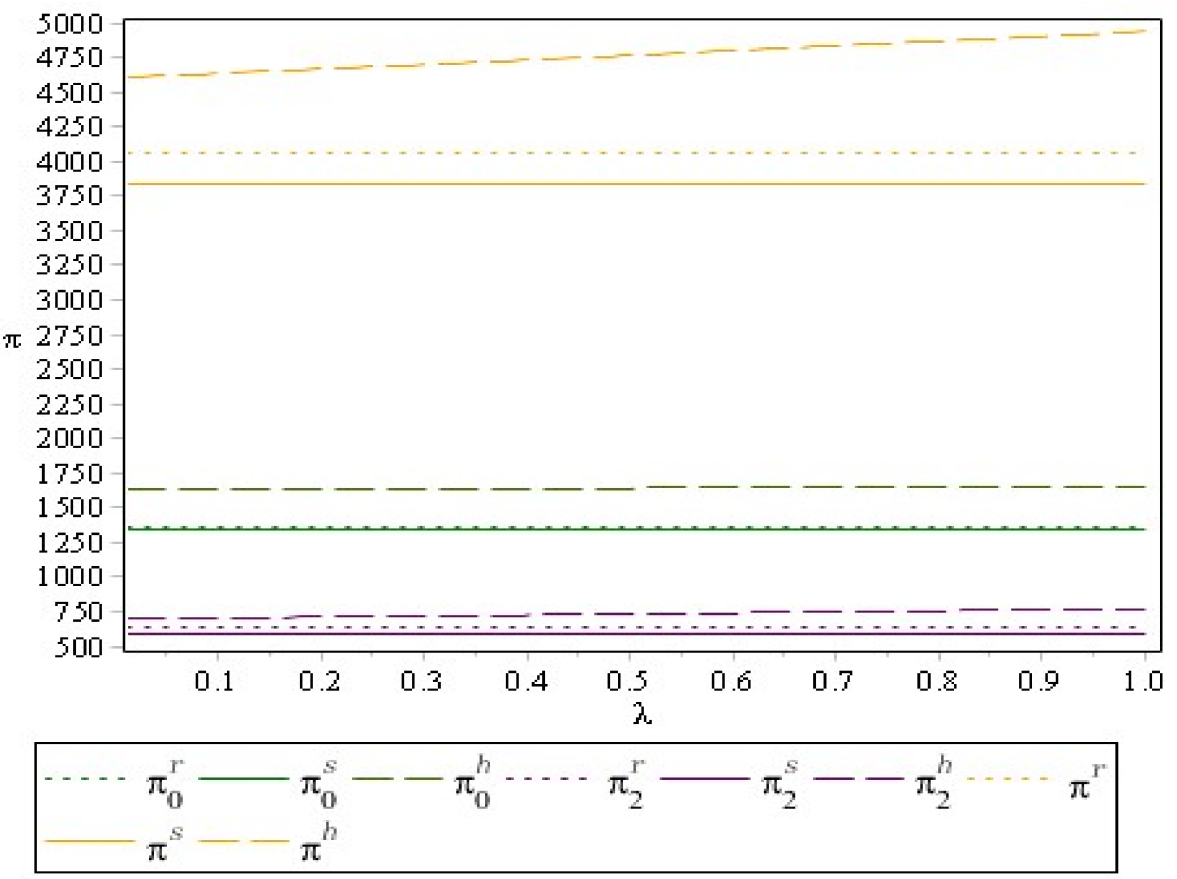

Figure 4. The profits of the supply chain members with different proportions of cost sharing $\lambda$ under the three decisions.

According to Tables 4 and 5 and Figure 4, with increasing proportion of the cost sharing, the profits of the members and whole supply chain increase, and are higher than those under the decentralized decision-making scheme when either the retailer or the suppliers are CSR alone. These results show that the coordination decision-making mechanism designed in this paper can achieve further Pareto improvement for the supply chain's performance, which is also consistent with Theorem 7 . The specific analysis is as follows.

Comparing the profits of each member in Tables 4 and 5, we can find that the profits of all members under a cost-sharing mechanism are higher than that of two cases in decentralized decision-making and the wide-system profits are higher than those without CSR in centralized decision-making in Table 1, which show that the cost-sharing mechanism cuts out the channel conflict and leads to win-win outcomes for the members in SC.

In Figure 4, the total profits of the retailer and three suppliers are increasing with the increasing of the cost sharing proportion of the retailer. Especially, there are two kinds of extremes: the case of sharing the proportion of $\lambda=0$ and $\lambda=1$, respectively. When the retailer shares no CSR of suppliers, i.e., $\lambda=0$, there is no incentive for suppliers and they will be not willing to exhibit CSR though their total profits under the co-commitment of CSR are higher than that of two cases in decentralized decision-making. However, when the retailer fully shares CSR of suppliers, i.e., $\lambda=1$, the total profits of the retailer and suppliers are the biggest, but the pure profit of retailer is decreasing and its shareholders' value is damaged, so it is infeasible in real business cooperation unless it is nonprofit organization with the goal of perfect welfare maximization. Therefore, only in $0<\lambda<\frac{1-(\mu-b c)}{\mu-b c}$ (where $\frac{1-(\mu-b c)}{\mu-b c} \leq 1$ ), this mechanism is effective and can result in a win-win situation.

Based on the analysis above, our proposed mechanism based on cost sharing of CSR is better than those with either the retailer or the suppliers being CSR alone. The profits of the supply-chain members under cost sharing of CSR are obviously larger than those under either the decentralized or centralized decision-making schemes; the optimal decision-making can more effectively heighten the enthusiasm of the stakeholders and realize the maximization of profits for the whole supply chain than the other decision-making mechanisms, and can effectively achieve further Pareto improvement 
in the supply chain's performance and mobilize the supply-chain members to exhibit CSR without compromising their profitability.

\section{Managerial Implications and Concluding Remarks}

In this paper, we have discussed the optimal decision-making in a socially responsible retailer-suppliers supply chain, where four cases are considered. In order to solve the coordination decision-making problem in a supply chain with CSR, we employ the concept of super conflict equilibrium to design a novel coordination decision-making mechanism based on the cost sharing of CSR. Through the analysis of the model and a case, the study yields the following insights.

(1) When suppliers have CSR, the wholesale price decreases with increasing level of CSR; especially, it may be less than the marginal cost above a threshold of CSR practice, which adversely affects the shareholders' profits, though the consumer surplus, accrued from suppliers, partially compensates the loss of net profits, and the total profits of suppliers are still lower than that when they are not CSR. That is to say, suppliers cannot maximize the profits of shareholders and stakeholders simultaneously. However, the total profits of the retailer increase with market demand and consumer surplus when the retailer exhibits CSR practice, and are higher than those when it is not CSR. Thus, the retailer, as the leader, should share parts of CSR with the suppliers in order to balance the profits of stakeholders and shareholders through a pre-determined mechanism.

(2) Whether it is in the centralized or the decentralized decision-making scheme, consumers benefit from the increasing CSR of the retailer and/or the suppliers because the selling price of the products decreases when the retailer or suppliers increase their CSR. Moreover, the chain-wide profit is also higher under the consideration of corporate social responsibility than that when social responsibility is not considered at all. In addition, comparing the profits in the centralized or the decentralized decision-making and in the centralized decision-making with or without CSR, we can find that collaboration with CSR between the retailer and suppliers results in higher SC profits. These results imply that the performance of the supply chain is positively correlated to the adopted level of CSR, which provides the theoretical reason for decision-makers to consider investing in CSR in the real business world.

(3) Our established mechanism based on cost sharing of CSR is better than those developed with either only the retailer or only the suppliers to be CSR. It can effectively coordinate the relationship among these players of the supply chain, resolve the channel conflict problem and leads to win-win outcomes for all parties involved. Being the leader in a supply chain with CSR, the retailer exhibits CSR and influences the other stakeholders to perform socially responsibly by sharing parts of its CSR to coordinate the suppliers in order to realize a long-term cooperation and a win-win situation. This produces a super conflict equilibrium between Nash equilibrium and Shapely equilibrium among the retailer and the suppliers. For a supply chain under cost sharing of CSR, the economic benefits of sustainability are built within the cost-sharing mechanism because of the increased profits. The stakeholders of the supply chain are motivated to improve the CSR performance due to the expectation of increased profits beyond moral requests.

(4) For managers in the supply chain, our proposed mechanism provides theoretical support and an operational procedure to integrate CSR into business routines. They can use such thoughts, as implied by the mechanism, to motivate all parties to collaborate in CSR, to achieve Pareto improvement of the supply-chain performance, to enhance the responsible competitiveness of enterprises, and eventually to realize the sustainable development of the supply chain.

(5) From the previous conclusions 1-3, it can be seen that the performance of the supply chain is positively correlated to the adopted level of CSR and supply chain members and suppliers are reluctant to assume CSR in the absence of incentives. Similarly, there is greater overall investment spending on CSR by the retailer; therefore, for policy makers, they should increase individual or systemic incentives (like government subsidies) for the CSR behaviors in the supply chain to promote coordinated development of the economy, the society and the environment. 
In general, our proposed coordination decision-making mechanism enriches the theory of corporate social responsibility and expands its range of application in the coordination and decision-making of supply chains of corporate social responsibility. However, this paper still suffers from limitations and extends future research directions as the following:

(1) The mechanism designed in this paper is based on assumptions of information symmetry, including demand and cost information. This is not realistic for some practical scenario. The designed mechanism may be developed by considering several price-sensitive and stochastic demands and such CSR investment costs that obey a certain distribution.

(2) For the convenience of calculation, the proportion of CSR cost sharing $\lambda_{i}$ of different suppliers is assumed to be the same, that is to say, no consideration is given to the preferences for CSR and the abilities to perform CSR of different suppliers. In order to enhance the practical acceptability of the mechanism designed in this paper, future studies could look at how to provide fair and reasonable allocation of CSR among suppliers and motivate all parties to actively perform CSR.

Acknowledgments: This work is partially funded by the National Natural Science Foundation of China (71503103), the Humanities and Social Sciences of Education Ministry (17YJC640233), the Natural Science Foundation of Jiangsu Province (BK20150157), the Social Science Foundation of Jiangsu Province (14GLC008), the Jiangsu Province University Philosophy and Social Sciences for Key Research Program (2017ZDIXM034), the Fundamental Research Funds for the Central Universities (2017JDZD06), and the Jiangsu Innovation Program for Graduate Education (SJCX17_0490). Even so, this work does not involve any conflict of interest.

Author Contributions: Yong Liu and Bing-ting Quan designed and wrote this article. Jiao Li and Jeffrey Yin-Lin Forrest examined the article and revised the article format.

Conflicts of Interest: The authors declare no conflict of interest.

\section{References}

1. Dyllick, T.; Hockerts, K. Beyond the business case for corporate sustainability. Bus. Strateg. Environ. 2002, 11, 130-141. [CrossRef]

2. Word Commission on Environment and Development (WCED). Our Common Future; Oxford University Press: Oxford, UK, 1987.

3. Van Marrewijk, M. Concepts and definitions of CSR and corporate sustainability: Between agency and communion. J. Bus. Ethics 2003, 44, 95-105. [CrossRef]

4. Van Marrewijk, M.; Werre, M. Multiple levels of corporate sustainability. J. Bus. Ethics 2003, 44, 107-119. [CrossRef]

5. Ageron, B.; Gunasekaran, A.; Spalanzani, A. Sustainable supply management: An empirical study. Int. J. Prod. Econ. 2012, 140, 168-182. [CrossRef]

6. Ashby, A.; Leat, M.; Smith, M.H. Making connections: A review of supply chain management and sustainability literature. Supply Chain Manag. Int. J. 2012, 17, 497-516. [CrossRef]

7. Amaesh, K.M.; Osuji, O.K.; Nnodim, P. Corporate Social Responsibility in Supply Chains of Global Brands: A Boundaryless Responsibility? Clarifications, Exceptions and Implications. J. Bus. Ethics 2008, 81, 223-234. [CrossRef]

8. Murphy, P.R.; Poist, R.F. Socially responsible logistics: An exploratory study. Transp. J. 2002, 41, $23-35$.

9. Hsueh, C.F. Improving corporate social responsibility in a supply chain through a new revenue sharing contract. Int. J. Prod. Econ. 2014, 151, 214-222. [CrossRef]

10. Panda, S.; Modak, N.M.; Basu, M.; Goyal, S.K. Channel coordination and profit distribution in a social responsible three-layer supply chain. Int. J. Prod. Econ. 2015, 168, 224-233. [CrossRef]

11. Panda, S.; Modak, N.M.; Pradhan, D. Corporate social responsibility, channel coordination and profit division in a two-echelon supply chain. Int. J. Manag. Sci. Eng. Manag. 2016, 11, 22-33. [CrossRef]

12. Panda, S.; Modak, N.M. Exploring the effects of social responsibility on coordination and profit division in a supply chain. J. Clean. Prod. 2016, 139, 5-40. [CrossRef]

13. Panda, S.; Modak, N.M.; Barrón, C.L. Coordinating a socially responsible closed-loop supply chain with product recycling. Int. J. Prod. Econ. 2017, 188, 11-21. [CrossRef]

14. Modak, N.M.; Panda, S.; Mishra, R.; Sana, S.S. A three-layer supply chain coordination in socially responsible distribution system. Tékhne 2016, 14, 75-87. [CrossRef] 
15. Modak, N.M.; Panda, S.; Sana, S.S. Pricing policy and coordination for a two-layer supply chain of duopolistic retailers and socially responsible manufacturer. Int. J. Logist. Res. Appl. 2016, 19, 487-508. [CrossRef]

16. Linthicum, C.; Reitenga, A.L.; Manuel, J. Social responsibility and corporate reputation: The case of the Arthur Andersen Enron audit failure. J. Account. Public Policy 2009, 29, 160-176. [CrossRef]

17. Komodromos, M.; Melanthiou, Y. Corporate Reputation Through Strategic Corporate Social Responsibility: Insights from Service Industry Companies. J. Promot. Manag. 2014, 20, 470-480. [CrossRef]

18. Li, Y.H.; Ni, D.B.; Tang, X.W. Signaling Quality in Supply Chains by Corporate Social Responsibility. Chin. J. Manag. Sci. 2017, 25, 38-47.

19. Carter, C.R.; Jennings, M.M. Social responsibility and supply chain relationships. Transp. Res. Part E 2002, 38, 37-52. [CrossRef]

20. Hutchins, M.J.; Sutherland, J.W. An exploration of measures of social sustainability and their application to supply chain decisions. J. Clean. Prod. 2008, 16, 1688-1698. [CrossRef]

21. Kovács, G. Corporate environmental responsibility in the supply chain. J. Clean. Prod. 2008, 16, 1571-1578. [CrossRef]

22. Dahlsrud, A. How corporate social responsibility is defined: An analysis of 37 definitions. Corp. Soc. Responsib. Environ. Manag. 2008, 15, 1-13. [CrossRef]

23. Panda, S. Coordination of a socially responsible supply chain using revenue sharing contract. Transp. Res. Part E 2014, 67, 92-104. [CrossRef]

24. Yue, J.F.; Austin, J.; Zhang, Z.M.; Chen, B.T. Pricing and advertisement in a manufacturer-Retailer supply chain. Eur. J. Oper. Res. 2013, 492-502. [CrossRef]

25. Giri, B.C.; Sharma, S. Manufacturer's pricing strategy in a two-level supply chain with competing retailers and advertising cost dependent demand. Econ. Model. 2014, 38, 102-111. [CrossRef]

26. Chen, T.H. Effects of the pricing and cooperative advertising policies in a two-echelon dual-channel supply chain. Comput. Ind. Eng. 2015, 87, 250-259. [CrossRef]

27. Ryan, J.K.; Sun, D.; Zhao, X.Y. Coordinating a Supply Chain with a Manufacturer-Owned Online Channel: A Dual Channel Model under Price Competition. IEEE Trans. Eng. Manag. 2013, 60, 247-259. [CrossRef]

28. Li, B.; Chen, P.; Li, Q.H.; Wang, W.G. Dual-channel supply chain pricing decisions with a risk-averse retailer. Int. J. Prod. Res. 2014, 52, 7132-7147. [CrossRef]

29. Munson, C.L.; Rosenbaltt, M.J. Coordinating a three-level supply chain with quantity discounts. IEEE Trans. 2001, 3, 371-384. [CrossRef]

30. Li, Y.F.; Su, Q.; Zheng, J. Optimal Order Coordination of the Supply Chain with Stochastic Demand and Quality Defective Materials. J. Syst. Manag. 2015, 24, 904-911.

31. Zhang, X.M.; Huang, C.X. Research on Decision-making Mechanism of Knowledge-Sharing in Reverse Supply Chain Enterprises. Chin. J. Manag. 2013, 10, 233-237.

32. Jeong, I.J. A centralized/decentralized design of a full return contract for a risk-free manufacturer and a risk-neutral retailer under partial information sharing. Int. J. Prod. Econ. 2012, 136, 110-115. [CrossRef]

33. Kong, G.; Rajagopalan, S.; Zhang, H. Revenue sharing and information leakage in a supply chain. Manag. Sci. 2013, 59, 556-572. [CrossRef]

34. Seifbarghy, M.; Nouhi, K.; Mahmoudi, A. Contract design in a supply chain considering price and quality dependent demand with customer segmentation. Int. J. Prod. Econ. 2015, 108-118. [CrossRef]

35. Govindan, K.; Popiuc, M.N. Reverse supply chain coordination by revenue sharing contract: A case for the personal computers industry. Eur. J. Oper. Res. 2014, 33, 326-336. [CrossRef]

36. Tsao, Y.C.; Sheen, G.J. Effects of promotion cost sharing policy with the sales learning curve on supply chain coordination. Comput. Oper. Res. 2012, 9, 1872-1878. [CrossRef]

37. Lee, Y.J.; Cho, R.K.; Paik, S.K. Supply chain coordination in vendor-managed inventory systems with stock out-cost sharing under limited storage capacity. Eur. J. Oper. Res. 2016, 248, 95-106. [CrossRef]

38. Ghosh, D.; Shah, J. Supply chain analysis under green sensitive consumer demand and cost sharing contract. Int. J. Prod. Econ. 2015, 164, 319-329. [CrossRef]

39. Zhou, Y.J.; Bao, M.J.; Chen, X.H.; Xu, X.H. Co-op advertising and emission reduction cost sharing contracts and coordination in low-carbon supply chain based on fairness concerns. J. Clean. Prod. 2016, 133, 402-413. [CrossRef]

40. Jiang, L.; Wang, Y.; Liu, D.M. Logistics cost sharing in supply chains involving a third-party logistics provider. Cent. Eur. J. Oper. Res. 2016, 24, 207-230. [CrossRef] 
41. Ni, D.B.; Li, K.W.; Tang, X.W. Social responsibility allocation in two-echelon supply chains: Insights from wholesale price contracts. Eur. J. Oper. Res. 2010, 207, 1269-1279. [CrossRef]

42. Yang, Y.X.; Zhou, G.G.; Liu, W.D. Coordination problem for closed-loop supply chain network based on corporate social responsibility. Comput. Integr. Manuf. Syst. 2011, 17, 1997-2004.

43. Guo, C.X.; Li, X.S.; Guo, Y.H. Coordination and Profit Sharing Strategies for Supply Chains to Perform Corporate Social Responsibilities. J. Ind. Eng. Eng. Manag. 2011, 25, 103-108.

44. Gao, J.H.; Han, H.S.; Hou, L.T.; Wang, H.Y. Decision-making and coordination in closed-loop supply chain with social responsibility. Comput. Integr. Manuf. Syst. 2014, 1453-1461.

45. Crifo, P.; Diaye, M.A.; Pekovic, S. CSR related management practices and firm performance: An empirical analysis of the quantity-quality trade-off on French data. Int. J. Prod. Econ. 2016, 171 Pt 3, 405-416. [CrossRef]

46. Wu, Y.; Li, H.Y.; Gou, Q.L.; Gu, J.B. Supply chain models with corporate social responsibility. Int. J. Prod. Res. 2017, 55, 1-28. [CrossRef]

47. Pedersen, E.R.; Andersen, M. Safeguarding corporate social responsibility (CSR) in global supply chains: How codes of conduct are managed in buyer-supplier relationships. J. Public Aff. 2006, 6, 228-240. [CrossRef]

48. Ni, D.B.; Li, X.; Tang, X.W. CSR Operations in Supply Chains: Mutual Incentive, CSR Allocation and Cooperation. Chin. J. Manag. Sci. 2015, 23, 97-105.

49. Kopel, M.; Brand, B. Socially responsible firms and endogenous choice of strategic incentives. Econ. Model. 2012, 29, 982-989. [CrossRef]

50. Ni, D.B.; Li, K.W. A game-theoretic analysis of social responsibility conduct in two-echelon supply chains. Int. J. Prod. Econ. 2012, 138, 303-313. [CrossRef]

51. Modak, N.M.; Panda, S.; Sana, S.S.; Basu, M. Corporate social responsibility, coordination and profit distribution in a dual-channel supply chain. Pac. Sci. Rev. 2014, 16, 235-249. [CrossRef]

52. Liu, Y.; Xiong, X.X.; Qian, W.Y.; Wang, Y.H. Benefit conflict equilibrium model manufacturer and suppliers with supper dominator. Chin. J. Manag. Sci. 2016, 24, 604-611.

(C) 2018 by the authors. Licensee MDPI, Basel, Switzerland. This article is an open access article distributed under the terms and conditions of the Creative Commons Attribution (CC BY) license (http:/ / creativecommons.org/licenses/by/4.0/). 